suggested that the two vehicles might be launched separately, possibly up to a year apart. But ESA scientists are not very happy with this suggestion, pointing out that a simultaneous launch is one of the attractions of the mission.

Weight problems are also causing concern to planners for the first Spacelab flight. This is still scheduled to take place in August 1981, a date that ESA officials are confident can be met even with considerable slippage in the shuttle test programme.

However as things stand at present, the shuttle may not be ready to provide enough thrust by this stage to launch the full Spacelab payload. The current shortage is about 1,300 pounds out of a total weight of about 65,000 pounds; and it could mean that some of the experiments already lined up for the first Spacelab flight may have to be dropped. (One encouraging piece of news to ESA officials is that the US Air Force appears to be planning to use Spacelab for some of its own manned space-flight missions.)

The space shuttle problems are already affecting other areas of NASA's activity. Scientists involved in the Voyager mission, for example, feel that if it had not been for these problems, they might have had access to some extra money this summer for additional experiments.

The greatest uncertainty at present, however, is over what the political effects of the shuttle's problems will be on support for future projects. NASA, with the support of both the Office of Science and Technology Policy and the Office of Management and Budget, is adamant that none of the existing programmes should be cut to provide the additional funds needed by the shuttle.

Dr Frosch told the Senate subcommittee that cancelling the Galileo project-at one time discussed as a distinct possibility-would only save $\$ 83$ million in 1980 , considerably less than the extra money needed by the shuttle; nor would much be gained by taking money from the space telescope. "We do not consider either of these reasonable ways of getting extra funds," he said.

But the concern is that Congress, having provided NASA with the extra shuttle costs largely on the grounds that the success of the programme is required for US Defense plans-in particular for launching surveillance satellites, will be reluctant to complement this with support for new space science missions.

The situation is already bleak following the decision of the Carter administration not to request any new starts for the fiscal year 1980 partly to ensure adequate support for space shuttle. (Among projects which NASA had submitted to OMB were plans for a shuttle-launched gamma-ray observatory, an orbiting imaging radar to Venus, and a mission o the comets Halley and Enke.)

"The roal question is going to be what the 1981 budget contains. A second year with no new starts could really put the science programmes in jeopardy; if the nation wants a vigorous space science programme, then you have to start something new," Professor A. Cameron of Harvard College Observatory, chairman of the National Academy of Science's space science board, said last week.

Of course, if there are no new starts in the 1981 budget request the fault will not lie entirely with space shuttle; equally important may well turn out to be President Carter's desire to greet an election year with an attempt at a balanced budget.

But the additional funding which NASA is currently seeking from Congress for 1980 (\$225 million above its original request), has not improved the situation. "We are still hopeful that our project will be funded, but we are not as optimistic as we were a month ago," says one of the scientists involved with the gamma-ray telescope, currently top of the NASA's space astronomy and astrophysics board's priority list for future projects.

The dangers in the current situation have not been lost to Senator Stevenson who, with fellow committee member and ex-astronaut Harrison (Jack) Schmitt, has been urging a more aggressive space programme on the administration for some time.

"The problem with the shuttle programme now seems to have been a serious underfunding in the early stages, something of which up to six weeks ago the Congress had been unaware. And now it has all come home to roost with a $15 \%$ cost over-run," Mr Stevenson said at the subcommittee hearing last week.

"The biggest cost may effectively be the end of the civilian space programme, since the real risk is that the price of the shuttle's difficulties will be taken out of the civilian side of our space efforts. And with the country in its present mood, this could well happen."

Not all observers are quite so pessimistic. But the problems raised for future space science funding are already being taken seriously, not only by NASA but also by both OSTP and OMB. And they will provide an unwelcome house-warming present to greet NASA's new associate administrator for space science, $\mathrm{Dr}$ Thomas Mutch, when he takes up his appointment next month.

\section{California plans to build world's largest telescope}

ThE University of California is in the midst of preparing preliminary designs for a 10-metre diameter optical telescope that planners hope will be operating in the mid-1980s. Two designs are being considered, each a radical departure from conventional optical telescopes, which would be prohibitively expensive to scale up to this size.

The proposed telescope would be by far the largest in the world, with a mirror twice the diameter of the Hale telescope on Mount Palomar. (Nominally the largest telescope in the world is now the $6 \mathrm{~m}$ at Zelenchukskaya Astrophysical Observatory in the Soviet Union, but western astronomers generally comment that it has not yet been proved reliable.)

Jerry Nelson, of Lawrence Berkeley Laboratory and chairman of the technical design committee for the proposed telescope told a meeting of Californian science writers last month that it would be designed to produce images smaller than 0.5 arc seconds and that, for good infrared observations, it would have to be built at a site with low atmospheric moisture.

Historically, the costs of optical telescopes with thick, monolithic glass mirrors have risen roughly as the cube of the diameter. This means that a conventionally designed 10-metre instrument would cost around $\$ 200$ million-a figure Nelson says is "out of the question". On the other hand, the design committee has already rejected such alternatives as the use of independently focused multiple mirrors, like the recently opened telescope at Mount Hopkins (Nature, 3 May, page 9). Such multiple mirror devices may provide an economical alternative for studying point sources, but the new University of California telescope must have angular field wide enough to encompass an extended image like a galaxy with associated star clusters.

Nelson's design committee has thus narrowed the acceptable options down to two: a single mirror much thinner than those used previously, or a segmented mirror with focusing characteristics approximating those of the monolithic design. In either case the anticipated principal focal length would be between 15 and 20 metres, which would facilitate a relatively small containment structure. Traditionally half the expense of building a new observatory has gone into the telescope and half into the surrounding structure, so every effort is being taken to minimise the overall size. 
The instrument will also be made more compact by the use of an altazimuth mount. Most large telescopes have been mounted with their axis of rotation parallel to that of the Earth, so that only one sweeping movement is required to track an object across the sky, but this so-called equatorial mount is relatively bulky. The advent of computer control has now removed the obstacles that once prevented use of the smaller but more complex altazimuth mount, which requires coordinated rotation about both the vertical and horizontal axes.

For either the thin continuous mirror or the segmented mirror, the question of how to evenly distribute the weight of the glass raises a host of unsolved problems. In either case 'active optics' will be required-that is, the stress on various support points must change continuously to prevent deformation of the glass when the mirror is tilted. The thin monolithic mirror would require some 100 to 200 support points, the majority of which must be active. On the other design, each segment of the composite mirror would require 12 sensors and 3 actuators to change its tilt and focus. On this point, at least, Nelson seems confident. "We think control is no problem," he says. A simple actuator device for segments of the composite mirror has already been tested and shown to be many times more precise than required, and the overall control scheme has been successfully modelled on a computer.

Preparing the glass, however, is another matter. A leading glass company has agreed to prepare the monolithic blank if that design is finally chosen, but many problems would remain in caring for the world's largest piece of fragile glassware. Among other things, the whole mirror, planned to be only 15 centimetres thick,

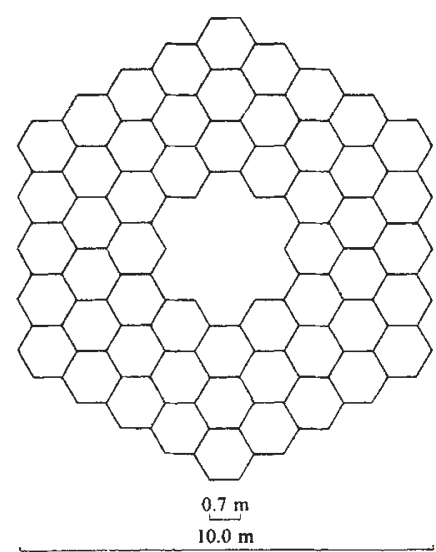

Possible segmented design for $10 \mathrm{~m}$ mirror

would have to be enclosed in a vacuum tank each year for realuminizing. The segmented mirror also under consideration would require nine basic segment shapes to produce an overall parabolic curvature. The polishing might be done by computer control on segments already prepared for mounting, or possibly by a cheaper method-which Nelson calls "extremely promising"-in which the pre-stressed segments are polished spherically then released to snap back into the shape of an off-axis parabola. The ten centimetre thick segments would be hexagonal, 0.7 metres on a side, and mounted in three rings around a larger central mirror. The completed composite mirror would contain 54 segments.

The final cost should be in the range of $\$ 20-50$ million, of which the university hopes to raise at least half initially and then try to obtain matching federal funds. If construction can begin by 1981 the new telescope might be completed by 1986 .

To avoid as much water vapour as possible, three relatively arid mountains have been proposed as possible sites. Mauna Kea, a 14,000 foot volcano in
Hawaii, would be the most accessible since the roads already lead to existing observatories on its peak. White Mountain in California, also 14,000 feet high, would be closer to the university's campuses, but the summit is almost unreachable by land vehicle: Junipero Serra Mountain is close to the UC Santa Cruz campus, which has a particularly active astronomy department, but with a height of only 6,000 feet it is by far the most moist of the three locations. Wherever the new observatory is built, the planners have already resigned themselves to building a structure sturdy enough to allow observations in the midst of $50 \mathrm{mph}$ winds.

NeIson and others involved in the project sound optimistic about being able to build their proposed observatory, despite its high cost and necessarily radical design. They point out four broad classes of observation that would be facilitated by the proposed instrument:

- With direct optical imaging, a 10metre telescope would permit better study of distant galaxies and a further attack on the problem of whether the universe will expand for ever or eventually collapse.

- Direct infrared observations would be used to study protostars and the structure of the galactic centreperhaps resolving the question of whether it contains a massive black hole.

- Optical spectroscopy using the new instrument would allow astronomers to study globular clusters around other galaxies and investigate why quasars have absorption lines.

- Finally, infrared spectroscopy could be used to determine the abundances of various molecules in stars, and to study the emission spectra of quasars.

John Douglas

\section{Sussex students step up science exam protest}

Protest escalated last week at the campus of Sussex University against a compulsory first-year preliminary science examination. Two students, Richard Flint, president of the student union and Shaun Fensom, an engineering student, were "excluded permanently" from campus by viceChancellor Sir Denys Wilkinson for their "leadership" of a student-unionmandated disruption of a resitting of the contested examination.

An emergency Senate meeting has been called for 13 June when the ViceChancellor will explain his action to the faculty.

Half the university's 4,000 students attended an emergency meeting on 5 June. They rejected a call for an immediate occupation of university buildings, but voted to canvass university and staff to protest against the expulsion and seek support from campus trade unions. They also decided on a series of one-day strikes the first of which was held last Friday with mass picketing at university entrances. The vice-chancellor was turned away. Students estimated that attendance was reduced to $10 \%-20 \%$ of normal but administration officials claimed that the action had not achieved its aim of stopping all classes.

The protest is taking a form not familiar since the $1960 \mathrm{~s}$. The original campaign began two years ago when the student union voted for direct student action to end a compulsory first-year examination in science subjects. The science division is the only one at Sussex with such a requirement. Arguing that the exam distorted teaching practices and served no useful assessment purpose, the union called for a boycott. In the first year the boycott was $65 \%$ effective.

In the meantime a nine-member faculty working party was set up to consider the students' demand. It rejected the students' proposal that the exam be made optional, citing a need for "rigorous training in discipline", "an ability to marshal facts under pressure and to meet deadlines" and the "necessity for an objective means to monitor progress" as reasons for its decision. The working party specifically 